\title{
Reduction of HC and CO in the Exhaust Gas of Minibus Vehicles by Natural Zeolite
}

\author{
Amru Siregar, Amirsyam Nasution
}

\begin{abstract}
Air pollution due to burning fossil fuels is still an environmental problem today. This paper presents the research results; method of reducing $\mathrm{HC}$ and $\mathrm{CO}$ in the exhaust gas of minibus vehicles. This method uses a pollutant gas trap (PGT) device, which functions as an adsorption medium, and natural zeolite as an absorbent material. The PGT device is designed in such a way that the zeolite can adsorb HC and CO gases flowing in it. The PGT device consists of a hollow body and supporting equipment arranged in it. The cavity of the PGT device is filled with zeolite granules and can be passed through vehicle exhaust gases. The PGT device consists of laminar and turbulent flow types, while the zeolite grains used are $2.54 \mathrm{~mm}$ and $1.27 \mathrm{~mm}$. The PGT-zeolite device is installed at the exhaust end of the vehicle, so that polluting gases are absorbed by the zeolite. The adsorption capability of the PGT-zeolite device was measured with an Automotive-Emission-Analyzer, type NHA-406EN. Turbulence type PGT device, capable of reducing pollutant gases $\mathrm{HC} \approx 40 \%$ and $\mathrm{CO} \approx 42 \%$ respectively for the zeolite grain size of $2.54 \mathrm{~mm}$. Meanwhile, the laminar flow type PGT device was able to reduce $\mathrm{HC} \approx 36 \%$ and $\mathrm{CO} \approx 42 \%$ gas, respectively for the zeolite grain size of $2.54 \mathrm{~mm}$. The results of this study indicate that the PGT-zeolite device has a very good ability to reduce pollutant gases in the exhaust gas of minibus vehicles. Therefore, it is necessary to continue research on the feasibility of using natural zeolite, as an absorber of polluting gases in other types of vehicles.
\end{abstract}

Keywords: Exhaust gas, Gas trap, Natural zeolite

\section{INTRODUCTION}

$F_{\text {ossil fuels are still the most widely used energy source }}$ today, especially energy sources for industrial activities, mining, transportation and power generation [1]. All of these activities will cause air pollution, especially those caused by burning fossil fuels from the transportation sector. Air pollution due to combustion of automotive engines consists of $\mathrm{CO}, \mathrm{CO}_{2}, \mathrm{NO}_{\mathrm{x}}, \mathrm{SO}_{2}$, particulate matter (PM), and other heavy metals [2-3]. Because the amount of air pollution emissions produced is relatively large, the use of fossil fuels will contribute to global warming, global climate change and the health of living things [4]. New data reveal that air pollution containing black hydrocarbon particles and some sub-micron-sized organic matter is a cause of global warming and climate change [5].

Manuscript received on August 13, 2021.

Revised Manuscript received on August 24, 2021.

Manuscript published on August 30, 2021.

* Correspondence Author

Amru Siregar*, Department of Mechanical Engineering, Faculty of Engineering, Medan Area University, Medan, Indonesia. Email: amrusiregar54@gmail.com

Amirsyam Nasution, Department of Mechanical Engineering, Faculty of Engineering, Medan Area University, Medan, Indonesia. Email: amirsyam@gmail.com

(C) The Authors. Published by Blue Eyes Intelligence Engineering and Sciences Publication (BEIESP). This is an open access article under the CC BY-NC-ND license (http://creativecommons.org/licenses/by-nc-nd/4.0/)
Apart from having an impact on climate change, exhaust emission also have an impact on living things. The CO gas produced will move quickly to various places. Both humans and animals will adsorb CO gas through the lungs, so that $\mathrm{CO}$ gas can be the cause of fatal poisoning and chronic side effects of $\mathrm{CO}$ in vascular disease [6]. Tackling air pollution has become the goal of a large number of studies and government policy directions, especially for air pollution problems caused by automotive engine exhaust emission [7].

There are several methods that can be used to reduce pollutants in automotive engine exhaust emissions. These methods include; development of fuel systems and the use of renewable fuels [8-10], development of combustion technology in internal combustion engines [11-12], timely maintenance of motor vehicles will contribute to reducing air pollution it causes [13], processing emissions gas from an automotive engine before it is released [14]. One way to process gas emissions before they are removed from the exhaust is to use a catalytic converter in the exhaust system. This method can reduce pollutants in exhaust gas emissions [15-16]. Apart from adding a catalytic converter to the exhaust system, pollution reduction can be done by the absorption method. The absorption system used consists of a gaseous pollutant trapping device. This trapping device is installed on automotive engine exhaust [17-18].

Natural zeolite is a potential natural resource because it is abundant on the earth's surface [19], and has many benefits. Zeolite is composed of hydrated aluminum-silicate compounds which have a porous structure. The main structure of a zeolite is a tetrahedron, the center of which is occupied by a silicon or aluminum atom, with four oxygen at the knot. Within the framework of this structure there is a fine cavity which is generally covered by cations, water molecules, and has a permanent negative charge. Due to its properties; adsorption, catalysis, ion exchange, and molecular sieves [20], zeolites are used widely in various fields. Natural and synthetic zeolites have been popularly used in the field of pollution reduction, among others; removes heavy metals from industrial wastewater [21-29], as a catalyst in reducing gas emissions [30], reduction of pollutant gases from automotive engine emissions [31-32].

The purpose of this study was to determine the effectiveness of natural zeolites as a pollutant adsorbent from the exhaust gas of a minibus vehicle engine. For this purpose, an adsorption medium between zeolite and pollutant gas has been designed. The adsorption medium that has been designed is a set of pollutant gas traps. These traps for pollutant gases consist of laminar and turbulent flows. The advantages of these two types of pollutant gas trapping will be investigated.

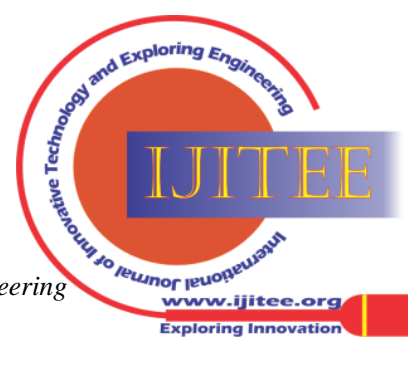




\section{MATERIALS AND METHODS}

\section{A. Natural Zeolite Preparation}

The materials used in this research is natural zeolites which is obtained in the market. Zeolite is obtained in the form of granules about 5 mesh $(\approx 5 \mathrm{~mm})$ in size. To obtain 10 mesh $(\approx 2.54 \mathrm{~mm})$ and 20 mesh $(\approx 1.27 \mathrm{~mm})$ zeolite granules, zeolite processed mechanically; milled and sieved. The next zeolite processing is physical and chemical treatment. This process aims to remove impurities and water content from the pores of zeolite granules. The result of this process is an increase in the total specific surface of the zeolite. It is very important to select a suitable treatment process, because the extreme treatment conditions can lead to structural collapse and a decrease in the crystallinity of the material [33]. Based on this consideration, the zeolite treatment is this study is as follows; zeolite granules were washed thoroughly, then heated in a heating furnace at a temperature of $200^{\circ} \mathrm{C}$, held for 3 hours. Furthermore, the chemical process, zeolite was immersed in a solution of 0.5 $\mathrm{M} \mathrm{H}-\mathrm{Cl}$ for 8 hours at room temperature. Then this zeolite was washed thoroughly and heated again to $200^{\circ} \mathrm{C}$, held for 3 hours. The zeolite granules produced from the initial step to the last process are activated zeolites. This selected sequence and conditions of physical and chemical process is one way of enhancing the properties of zeolites [34].

\section{B. Pollutant Gas Trapping Device}

The pollutant gas trapping (PGT) device is designed as

shown in Fig. 1-2. The geometric shape of this PGT device refers to the engine exhaust of a minibus vehicle. Minibus vehicle engine exhaust was chosen as a reference because minibus vehicles are the object of this research. There are two types of PGT devices, namely laminar and turbulent flow types. The construction of the PGT device consists of a combination of body parts, gas emission line pipes and hollow balls. The hollow balls will be filled with zeolite granules, so they must be covered with mesh wire as shown in Fig. 3-4. The hollow balls filled with zeolite grains are inserted into the gas emission pipe. The arrangement of the components of the PGT device like this allows the adsorption of pollutant gases by zeolites. The mass of the pollutant gas that is adsorbed is proportional to the mass of the emissions gas that enter the ball cavity. The greater the mass of emission gas flowing through the spherical cavity, the greater the mass of pollutant gases adsorbed.

\section{Gas Emission Testing Procedures}

The emission gas test equipment used is the AutomotiveEmission-Analyzer, NHA-406EN type. This emission gas

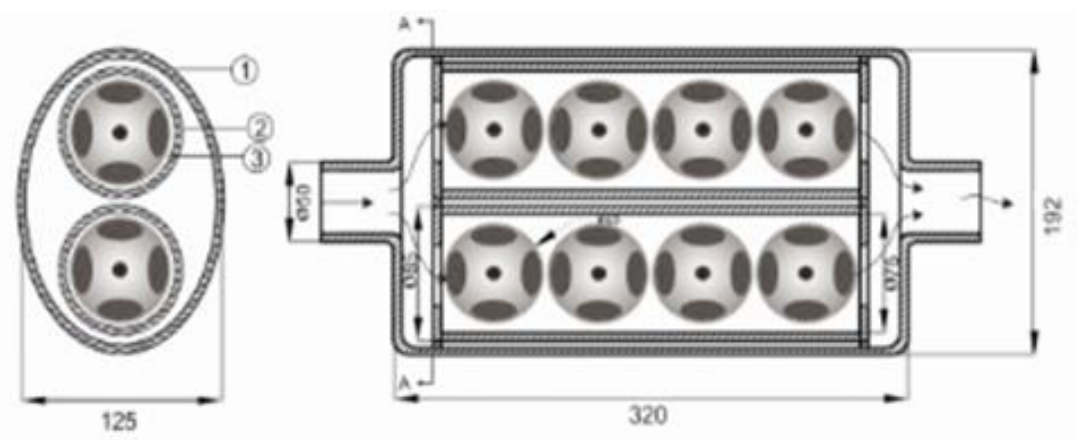

Fig. 1 Laminar flow type pollutant gas trapping device, composed of (1) body part, (2) gas emission pipe (3) hollow ball covered with wire mesh
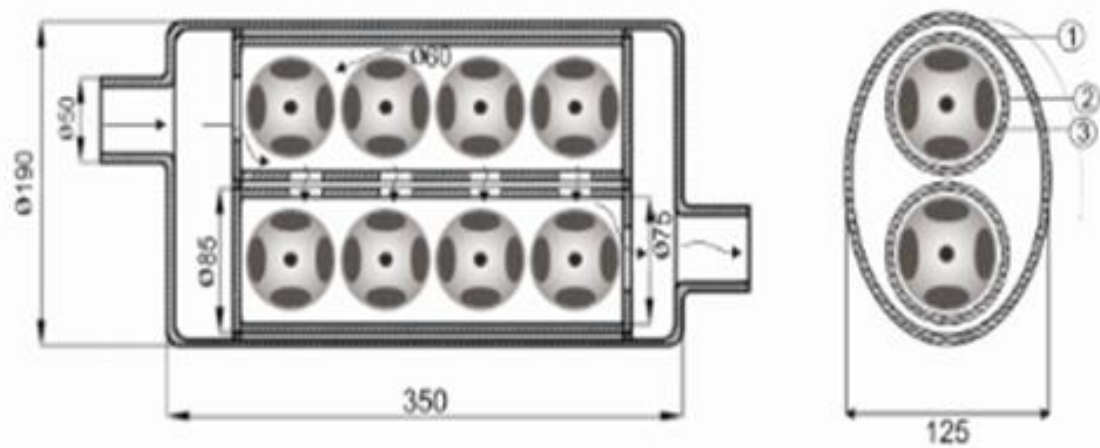

Fig. 2 Turbulent flow type pollutant gas trapping device, composed of (1) body part, (2) gas emission pipe (3) hollow ball covered with wire mesh 


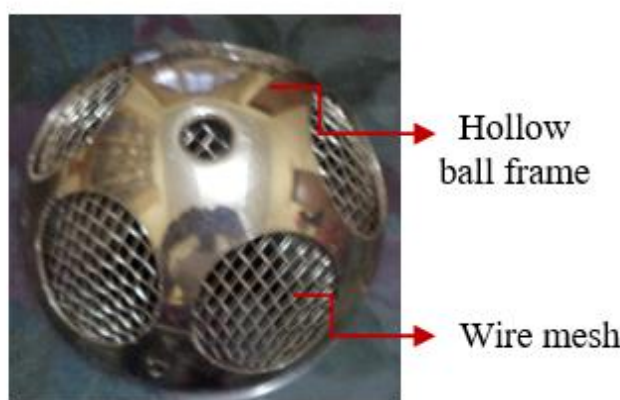

Fig. 3 The ball is wire meshed

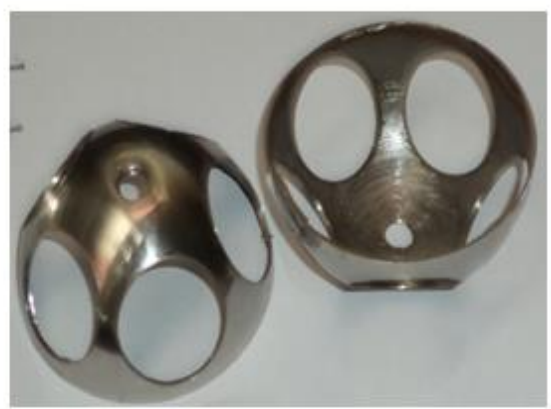

Fig. 4 Hollow ball frame

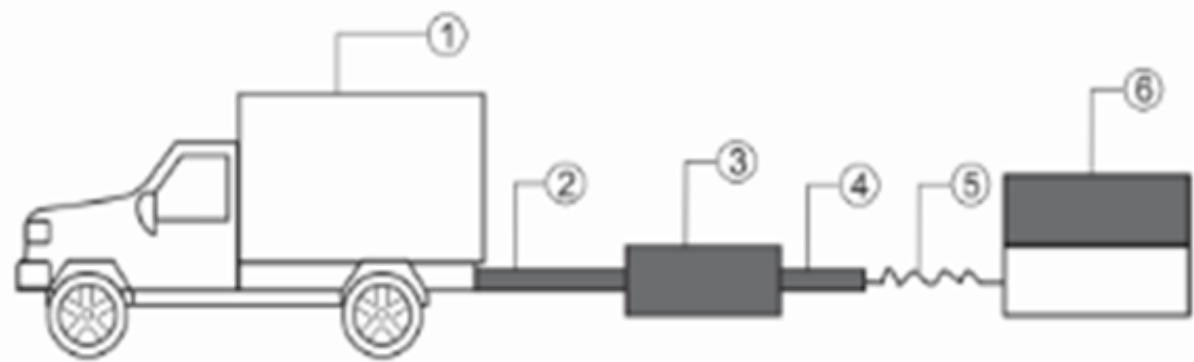

Fig. 5 Sketch of gas emission testing equipment settings, the names of the parts; (1) minibus vehicles, as test objects, (2) minibus exhaust, (3) pollutant gas traps, (4) gas passage pipe and emission test gauge sensor, (5) sensor connecting wire, (6) exhaust gas emission test equipment.

tester can only detect gases; $\mathrm{CO}, \mathrm{CO}_{2}, \mathrm{O}_{2}$ and $\mathrm{HC}$ [35]. The first activity carried out in the testing process was measuring the emission composition of the mini bus engine, without using PGT device. The activity begins with the preparation of gas emission testing equipment. The emission gas sensor is placed in the exhaust cavity and connected to the monitor. When the emission gas flows through the exhaust cavity, the sensor will respond and send a signal to the monitor. The response that appears on the monitor can be read, so the emission gas composition is obtained. The data obtained in this initial measurement will be used as reference data.

The second stage activity in the testing process is the measurement of the emission gas composition of the mini bus vehicles, which are equipped with PGT device. The PGT device are arranged in series with the engine exhaust of minibus vehicles. The arrangement of the emission gas test equipment is shown in Fig. 5. When the emissions gas comes out of the engine exhaust and into the cavity of the PGT device; which has a gas emission sensor installed in it, the sensor will respond and send a signal to the central processing unit (CPU). The test value can be read on the monitor, so that the emission gas composition value is obtained. With the same procedure test for 25 minibus vehicles. Each minibus vehicles is test with variations; laminar and turbulent flow type PGT devices, for zeolite grain size $\approx 2.54 \mathrm{~mm}$ and $\approx 1.27 \mathrm{~mm}$, respectively. The adsorption efficiency of each vehicles unit is calculated by equation (1) and the average adsorption efficiency of the PGT device is calculated by equation (2):

Adsorption efficiency $(\%)=\frac{q_{i-} q_{o}}{q_{i}} \times 100$

adsorption efficiency average (\%)

$$
=\frac{1}{n} \sum_{m=1}^{n}\left[\frac{\left(q_{i}-q_{o}\right)}{q_{i}}\right]_{m} \times 100
$$

Where $q_{i}$ : pollutant gas content without using a PGT device (\%), $q_{0}$ : pollutant gas content by using a PGT device (\%), and $\boldsymbol{n}$ is the number of minibus vehicles test ( $\boldsymbol{n}=25$ units).

\section{RESULTS AND DISCUSSION}

The adsorption efficiency of zeolite against $\mathrm{HC}$ and $\mathrm{CO}$ gas with PGT media is influenced by factors namely; the geometric shape of the PGT device, and the grain size of the zeolite. The change in geometric shape causes differences in gas flow within the PGT devices, as shown in Fig 1-2. The geometric shapes of the PGT device includes; shape,

dimensions and arrangement of its components. The PGT device in Fig. 1, the emission gas enters one end of the pipe, flow into the pipe, traverses the spherical cavity, comes into contact with the zeolite, then exits the other end. In Fig. 2, gas emission enters one end of the pipe, flows in the pipe, traverses the spherical cavity, comes into contact with the zeolite, then changes direction, and/or rotates, enters another pipe, crosses the ball cavity, makes contact with the zeolite, then exits through the other end of the pipe. Due to this difference in gas flow, PGT devices are divided into laminar and turbulent flow types.

The mass amount of $\mathrm{HC}$ and $\mathrm{CO}$ gas adsorbed is determined from the different in the amount of gas adsorbed without using a PGT devices and the amount of gas adsorbed using a PGT device. The calculated $\mathrm{HC}$ and $\mathrm{CO}$ gas adsorption efficiency values are presented in Fig. 6-14.

Published By:

Blue Eyes Intelligence Engineering and Sciences Publication

(C) Copyright: All rights reserved.

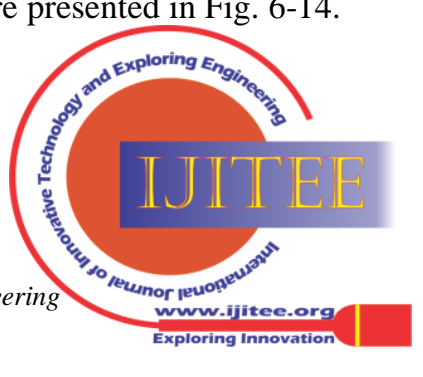


The influence of the geometric shape of the PGT device; for HC gas is depicted in Fig. 6-7, and for CO gas is depicted in Fig. 9-10. The effect of zeolite grain size on the adsorption of HC gas is depicted in Fig. 11-12, and the adsorption of CO gas is depicted in Fig. 13-14. While the average adsorption efficiency is depicted in Fig.8.

\section{A. Effect of Type of Emission Gas Flow}

In Fig. 6-7, it can be seen that in most test vehicles, the ability of the PGT device to adsorb HC gas is greater in the turbulent flow type, but in a small number of test vehicles, the ability of the PGT device to adsorb HC gas is greater in the laminar flow type. However, when added together, the average adsorption efficiency value is greater in the turbulence-type PGT device, shown in Fig.8a. While in Fig.9-10, the value of CO gas adsorption efficiency is shown, for the use of laminar and turbulent PGT devices. In general, the adsorption efficiency of $\mathrm{CO}$ gas tends to be the same as the adsorption efficiency of HC gas. The adsorption efficiency is greater when using the turbulence type PGT devices.

If we review the emissions gas flow in the turbulence type PGT device; emission gas enters from one end of the pipe, flows in the pipe, enters and flows through the spherical cavity, flows in the gap between the balls, in the gap between the ball and pipe, then reverses direction, and/or rotates, into the other pipe, through the cavity ball and flows out through one end of the pipe. This form of the passage of the gas flow causes it to occur; turbulence, the length of the path increases, and the flow speed decreases.

These parameters will affect the adsorption capacity of pollutant gases. The decrease in flow rate will increase the adsorption capacity. This statement is consistent with the results of a study published by CHANAN et al. [36]. The effect of turbulence and increasing the length of the gas flow path will increase the time and surface area of the contact. Increasing the contact time will increase the adsorption capacity, and the amount of mass adsorbed is a function of the contact time. This statement refers to the results of research published by TAAMNEH et al. [24], DJAMBAZOV et al. [37], Wang et al. [38], and MEHDIZADEH et al. [39]. The turbulent flow of emission gas will affect the zeolite adsorption capacity. The higher the turbulence, the higher the adsorption capacity, this is in accordance with the results of research published by Huang et al. [40].
Another case with the emission gas flow in laminar type PGT devices, the path length and contact time of the gas flow are smaller; gas emission enter through one end of the pipe and exit directly at the other.The length of flow path and the gas contact time are smaller; parallel gas emission flow in the two pipes, the emission gas enters from one end of the pipe, enters the ball cavity and exits at the end other. The effect of the type of emission gas flow in the PGT device, and the effect of the zeolite grain size, is also shown in Fig.8. In Fig. 8a, the average adsorption efficiency value of HC gas in the use of grain sizes $\approx 2.54 \mathrm{~mm}$ and $\approx 1.27$ $\mathrm{mm}$, respectively, was greater in the type of turbulence. The same thing is shown in Fig. 8b, for $\mathrm{CO}$ gas, the average adsorption

efficiency value for grain sizes $\approx 2.54 \mathrm{~mm}$ and $\approx 1.27$ $\mathrm{mm}$,

respectively, were greater for the turbulence type.

\section{B. Effect of Zeolite Grain Size}

The value of the adsorption efficiency of $\mathrm{HC}$ and $\mathrm{CO}$ gases in a number of test vehicles, viewed from the variation in grain size of natural zeolites, is shown in Fig. 11-14. In Fig. 11-12 presents the adsorption efficiency of HC gas. Fig. 11, for laminar type PGT devices and Fig.12 for turbulence type PGT devices, each with variations in grain size zeolite. In most of the test vehicles, the adsorption efficiency was greater for the use of zeolite with a grain size of $\approx 2.54 \mathrm{~mm}$, but in a small proportion of tested vehicles, the adsorption efficiency was greater when using a grain size of $\approx 1.27 \mathrm{~mm}$. The same is true for CO gas as shown in Fig.13-14. The adsorption efficiency was greater for the use of zeolite grain size of $\approx 2.54 \mathrm{~mm}$, in most of the vehicles tested, but in several other test vehicles, the absorption efficiency was greater for the use of zeolite grain size $\approx 1.27 \mathrm{~mm}$. However, overall, the average adsorption efficiency value was greater for the use of zeolite with grain size $\approx 2.54 \mathrm{~mm}$, as shown in Fig.8. From the above explanation, it can be stated that the use of large grain size zeolite results in greater adsorption efficiency. These results apply to the use of both turbulence and laminar type PGT devices.

To explain the above results, parameters of zeolite grain size are needed. Because natural zeolite is a porous material, the parameter used is the specific surface area. In theory, it is explained that porous materials with smaller grains have a

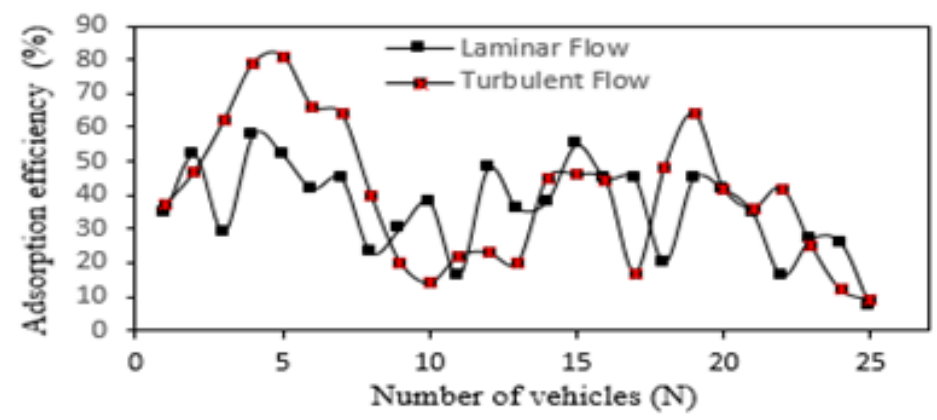

Fig. 6 Adsorption efficiency of $\mathrm{HC}$ pollutant gas using laminar and turbulent flow type PGT devices, for zeolite grain size $\approx 2.54 \mathrm{~mm}$ 


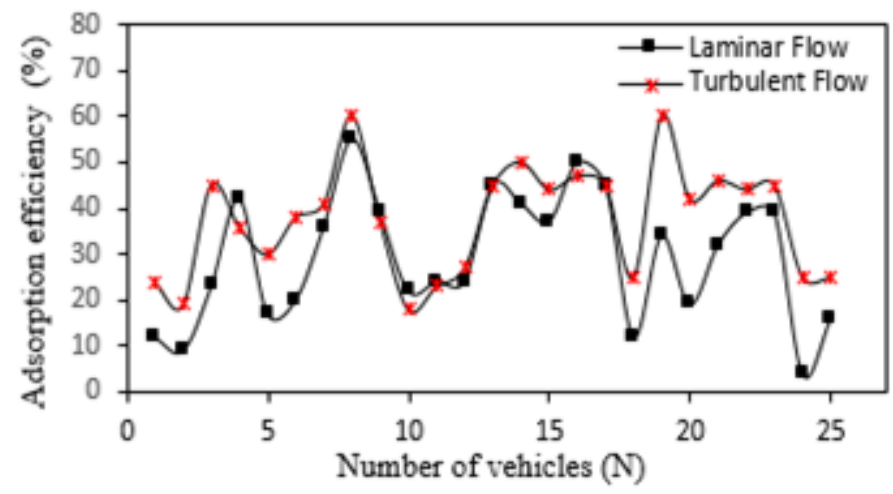

Fig. 7 Adsorption efficiency of $\mathrm{HC}$ pollutant gas using laminar and turbulent flow type PGT devices, for zeolite grain size $\approx 1.27 \mathrm{~mm}$
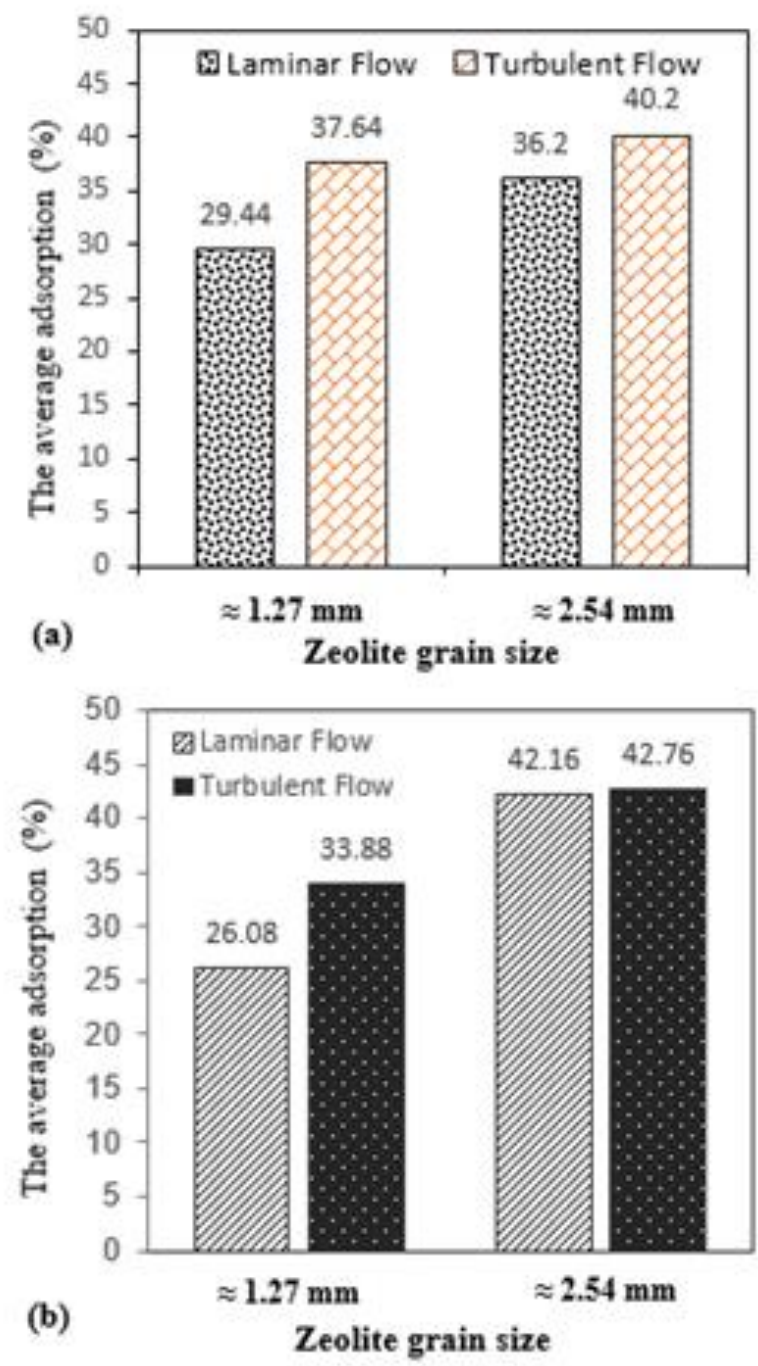

Fig. 8 The relationship between the average adsorption efficiency of pollutant gases, grain size of natural zeolites, laminar and turbulent flow of the PGT device; (a) for HC gas, and (b) for CO gas

larger specific surface area, so that materials with smaller grain sizes have a greater adsorption capacity [41]. However, the results obtained in this study contradict this theory; on the use of larger grains results in a greater adsorption efficiency. In the several references found, there are several research results that are in accordance with the theory, and some are contrary to the theory mentioned above. Research results published by Azim et al. [27], and Salman et al. [28],

according to the theory above. While the results of research published by ZORVAS et al. [42], stated that increasing the particle size will increase the adsorption efficiency. Another case with the results of research published by WINGENFELDER et al. [43], stated that there is very little effect of grain size on metal adsorption, but that smaller particles bind to less metals, and larger particles are bound to a greater amount of mass. ÖREN et al. [44], stated that the effect of zeolite grain size on metal adsorption is not very clear. It seems that the change in adsorption capacity does not depends only on changes in the outer surface area, but on the total surface area of the grains. The effect of changes in the outer surface area of the grains has very little effect on the total surface area of the grains, because the contribution of the outer surface area to the total surface area of the grains is not significant. Therefore, the effect of reducing grain size on the adsorption capacity is negligible [44]. From the descriptions above it can be understood that the adsorption efficiency of $\mathrm{HC}$ and $\mathrm{CO}$ gases is influenced by; type of PGT device and zeolite grain size. In addition to the influence of the type of PGT device and grain size, the influence of the diameter of the ball and wire mesh inlets, as shown in Fig. 3-4. The size of the mesh holes on the ball is adjusted to the grain size of the zeolite used. These wire mesh holes are the entrance to the gas flow; the holes are smaller if the grains are small, and the holes are bigger if the zeolite grains are bigger. So less gas enters through the small wire mesh holes and more enters through the larger holes. The size of the holes in the wire mesh affects the adsorption capacity. As a result, the adsorption of pollutant gases is less in smaller grains.

The following are the advantages of the adsorption capacity of the turbulence type PGT device compared to the laminar type. In Fig. 8a for HC gas, there is an advantage of the turbulence type of about $4.0 \%$ for the use of $\approx 2.54 \mathrm{~mm}$ zeolite grain size and about $8 \%$ for $\approx 1.27 \mathrm{~mm}$ zeolite grain size. As well as in Fig. 8b for CO gas, there is about $0.6 \%$ advantage of turbulence for a zeolite grain size of $\approx 2.54$ $\mathrm{mm}$ and about $7 \%$ for a grain size of $\approx 1.27 \mathrm{~mm}$. Thus it can be stated that the use of the turbulence type PGT device is more profitable than the laminar flow type.

Published By:

Blue Eyes Intelligence Engineering and Sciences Publication

(C) Copyright: All rights reserved.

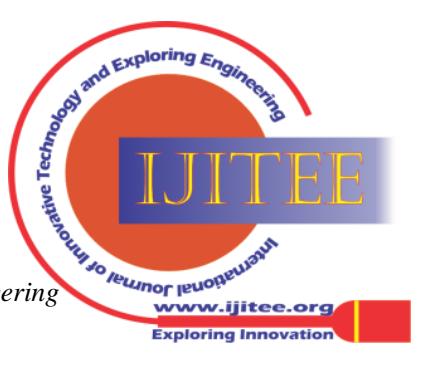


From the results of this analysis, it was stated that the use of the turbulence type PGT device could reduce HC gas by about $40 \%$ and CO gas by about $42 \%$ for $\approx 2.54 \mathrm{~mm}$ zeolite grain size. However, for the use of the laminar type PGT device, it can only reduce HC gas by about 36\% and
CO gas by about $42 \%$, each for a zeolite grain size of $\approx 2.54$ $\mathrm{mm}$.

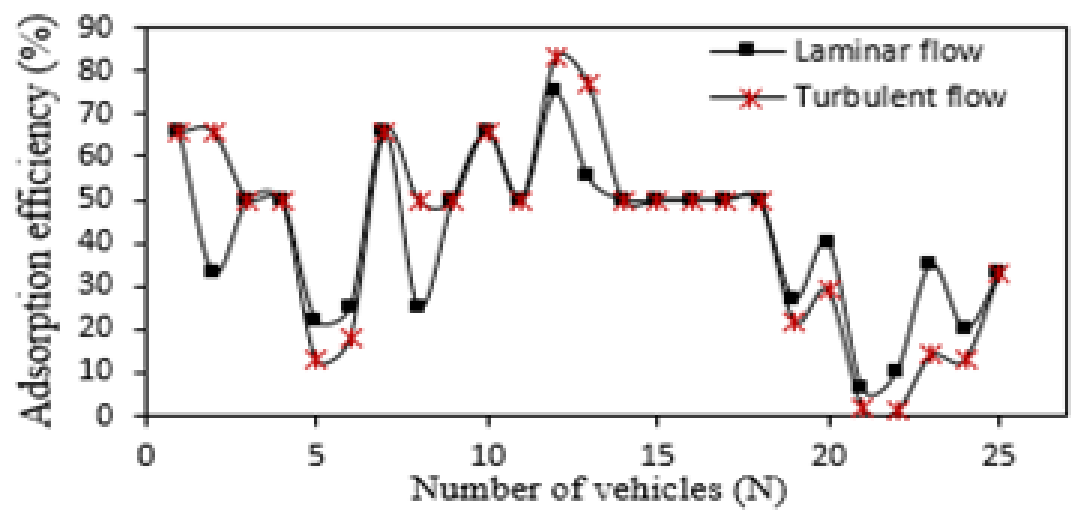

Fig. 9 Adsorption efficiency of $\mathrm{CO}$ pollutant gas using laminar and turbulent flow type PGT devices, for zeolite grain size $\approx 2.54 \mathrm{~mm}$

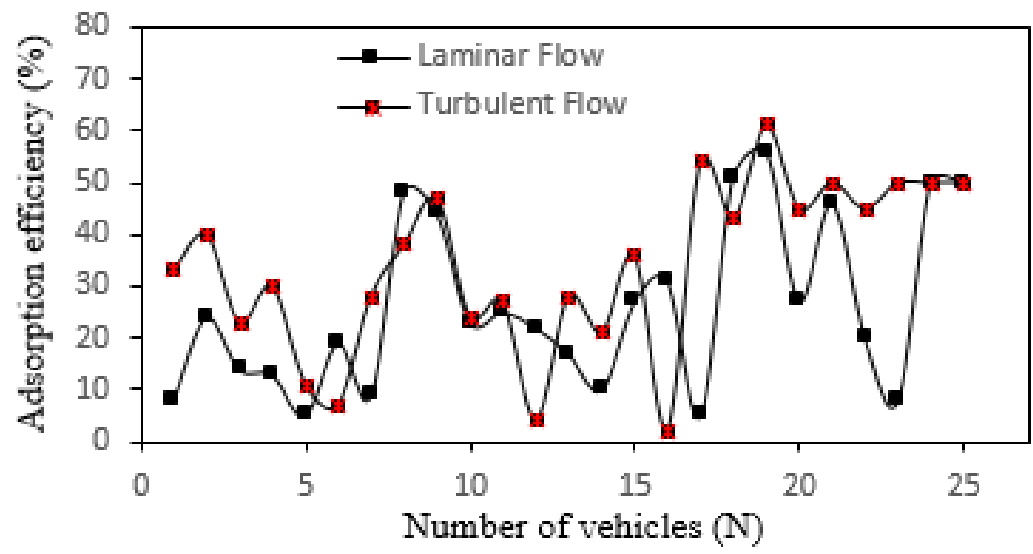

Fig. 10 Adsorption efficiency of $\mathrm{CO}$ pollutant gas using laminar and turbulent flow type PGT devices, for zeolite grain size $\approx 1.27 \mathrm{~mm}$

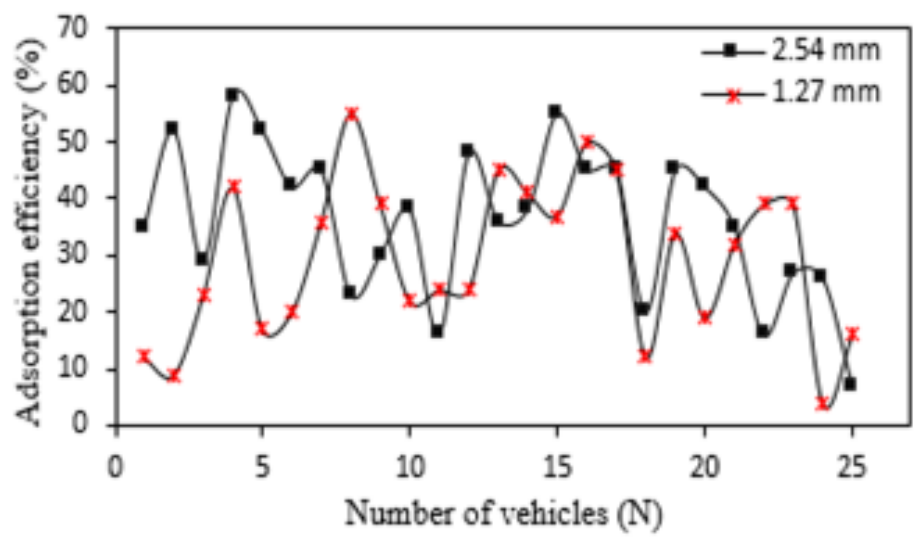

Fig. 11 The relationship between the HC gas adsorption efficiency on the number of vehicles tested, zeolite grain size variations, for laminar flow type PGT devices

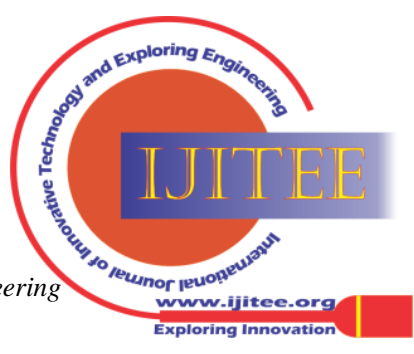




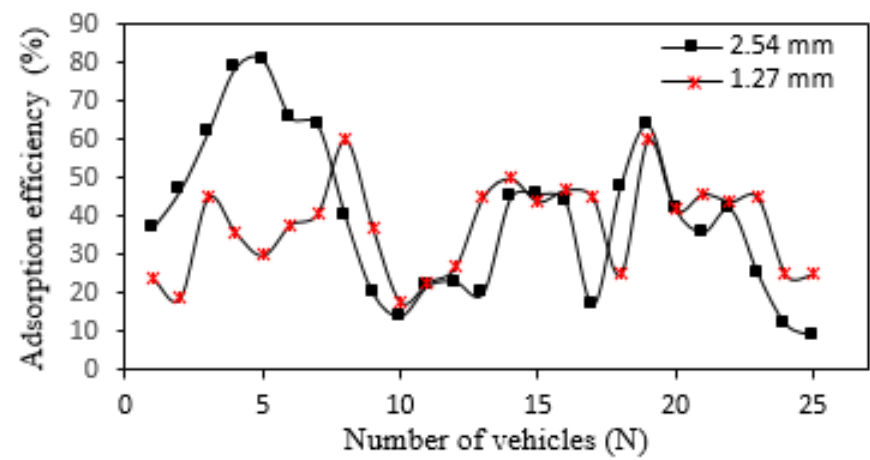

Fig. 12 The relationship between the $\mathrm{HC}$ gas adsorption efficiency on the number of vehicles test, zeolite grain size variations, for turbulence type PGT devices

\section{CONCLUSION}

The reduction of $\mathrm{HC}$ and $\mathrm{CO}$ pollutant gases from the exhaust gas of minibus vehicles has been carried out by; natural zeolites as adsorbents and Pollutant gas trapping (PGT) device as adsorption media. The PGT-zeolite device is effective in reducing $\mathrm{HC}$ and $\mathrm{CO}$ gas from the exhaust gas of minibus vehicles. The adsorption efficiency is influenced by the geometry of the PGT device, the size of the ball cavity inlets and the grain size of the zeolite. The use of turbulence type PGT devices is more profitable than laminar flow type PGT devices. The turbulence type PGT device can reduce HC gas by about $40 \%$ and CO gas by about $42 \%$, respectively for the use of zeolites with grain size $\approx 2.54 \mathrm{~mm}$. The laminar type PGT device can reduce HC gas by about $36 \%$ and CO gas by about $42 \%$, respectively for the use of zeolites with grain size $\approx 2.54$ $\mathrm{mm}$. Further research is still needed on the feasibility of using natural zeolites as an adsorbent for the exhaust gas of minibus vehicles. The PGT device design approach is in accordance with ergonomic principles in relation to; The adsorption effectiveness as a function of the duration of use and the mass amount of zeolite, the adsorption effectiveness as a function of the geometric shape of the PGT device.

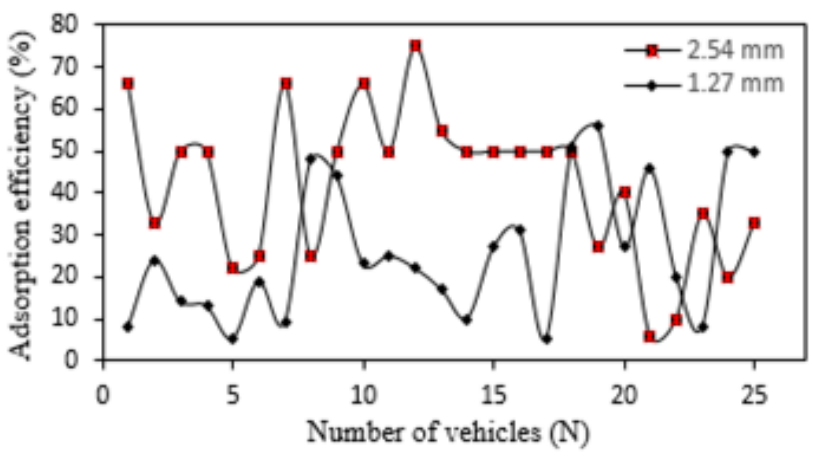

Fig. 13 The relationship between the $\mathrm{CO}$ gas adsorption efficiency on the number of vehicles tested, zeolite grain variations, for laminar type PGT devices

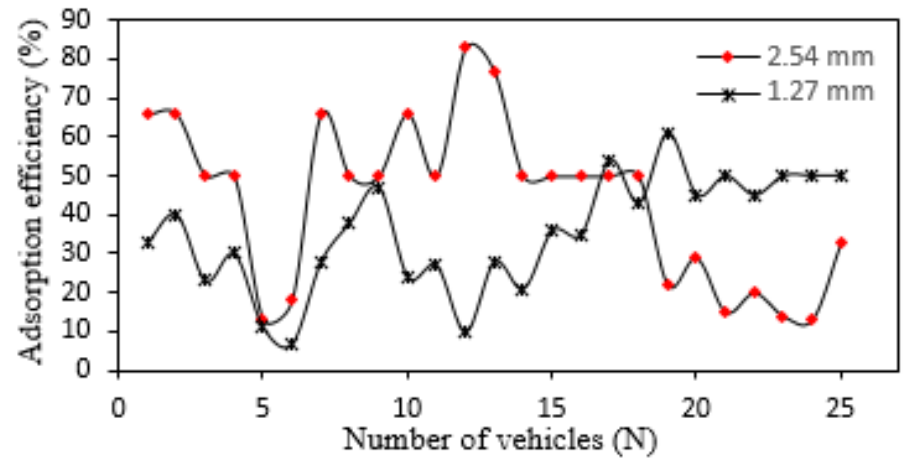

Fig. 14 The relationship between the $\mathrm{CO}$ gas adsorption efficiency on the number of vehicles tested, zeolite grain variations, for turbulence type PGT devices 


\section{ACKNOWLEDGEMENT}

This research was carried out well thanks to the help and cooperation of various parties. Therefore, on this occasion the author would like to thank you very much; to the Head of the Hajj Education Foundation, AGUS SALIM, who has provided funding for this research through the DIYA Program. Furthermore, to the Chancellor of the Medan Area University, as well as the Institute for Research and Community Service, Medan Area University, who have provided full support for the implementation of this research activities.

\section{REFERENCES}

1. WIRTZ C. Energy, Transport and Environment Statistics, STATISTICAL BOOKS. Publications Office of the European Union. Belgium. IMPRIMERIES BIETLOT FRERES. 2019. Retrieved from https://ec.europa.eu> documents >KS-DK-19-001-EN-N; November 14, 2020.

2. MOURA PCM, REICHMUTH D and GATTI D. Inequitable Exposure to Air Pollution from Vehicles in Massachusetts. Union of Concerned Scientists 2019; Retrieved from https://www.jstor.org/ stable/resrep 24098; November 14, 2020.

3. Air and water pollution: An important nexus of transportation and health. Transportation and Public Health. 2019; 65-106. Retrieved from https://www.sciencedirect.com>pii; November 14, 2000.

4. RAMANATHAN V. and FENG Y. Air pollution, Greenhouse Gases and Climate Change: Global and Regional perspectives. Atmospheric Environment 2009; 43(1): 37-50.

5. Herndon M. Air Pollution, Not Greenhouse Gases: The Principal Cause of Global Warming. Journal of Geography, Environment and Earth Science International 2018; 17(2): 1-8.

6. Stanley T.O. Metabolic Modulation of Carbon Monoxide Toxicity. Toxicology 2002; 180: 139-150.

7. Yana J, Henrik A and Zhang S. Air Pollution Control Policies in China: A Retrospective and Prospects. International Journal of Environmental Research and Public Health 2016; 13(12): 12-19.

8. MOFIJUR $\mathrm{M}$, RASUL M, HASSAN NMS, UDDIN MN Investigation of exhaust emissions from a stationary diesel engine fuel with biodiesel. Energy Procedia 2019; 160: 791-797.

9. ABED A.K, GAD S.M, El-MORSI K.A, SAYED M.M. Effect of biodiesel fuels on diesel engine emission. Egyptian Journal of Petroleum 2019; 28: 183-188.

10. James S.P, Busch S, McCormick L.R, Pihl A.J, Splitter A.D, Ratcliff A.M, Scott S, Miles P. What fuel Properties Enable Higher Thermal Efficiency in Spark-Ignited-engine. Progress in Energy and Combustion Science 2020; 00: 34-40. Ignition Engines. Progress in Energy and Combustion Science 2017; 61: 78-112.

12. KHALILIKHAH O and SHALCHIAN M. Modelling and FuzzyThreshold Control of SI Engine for Emission Reduction during Cold Engineering 2019; 16(4): 7225-7242.

13. VIANNA S.N.J, REIS V.A, OLIVEIRA S.B.A, SOUSA T.M. Reduction of Pollutants Emissions on SI Engines-Accomplishments with Efficiency Increase. Journal of the Brazilian Society of Mech. Sci. and Eng. 2005; 27(3): 217-222.

14. Asif F, Bhakta B.B, Kumar N. The Role of Inspection and Maintenance in Controlling Vehicular Emissions in Kathmandu Valley. Atmospheric Environment 2006; 40(31): 5967-5975.

15. GADLEGAONKAR N, PATIL V, PARDESHI V, BAJGUDE T, PATEL A. Design and Analysis of Catalytic Converter of Automobile Engine. International Research Journal of Engineering and Technology 2019; 06(5): 7637-7644.

16. Rahman A.A. On The Emissions from Internal-Combustion Engines: A Review. International Journal of Energy Research 1998; 22: 483513.

17. VENKATESH, V, JAIKUMAR M, MYLAUDY, S RAJADURAI. CO Capture by Using Modified ZMS-5 Zeolite in Diesel Powered Vehicle. IOSR Journal of Mechanical and Civil Engineering 2016; 13: 2278-1684.

18. CAPUTO D, COLELLA C, LUCOLANO F, CORBO P, MIGLIARDINI F, AIELLO R, CREA F. Reduction of Hydrocarbon
11. Wang Z, Liu H and Reitz D.R. Knocking Combustion in SparkStart Phase. International Journal of Automotive and Mechanical

Emission from Engine Exhaust Using Zeolite Adsorbent. Studies in Surface Science and Catalysis 2004; 154 (B).

19. Wang S, Peng Y. Natural zeolites as effective adsorbents in water and wastewater treatment. Chemical Engineering Journal 2010; 156: 11 24.

20. KULEYIN A. Removal of phenol and 4-chlorophenol by surfactantmodified natural zeolite, Journal of Hazardous Materials 2007; (144): 307-315.

21. Wang X, Shao D, Hou G, Wang XK, Alsaedi A, Ahmad B. Uptake of $\mathrm{P}$ b (II) and U (VI) ions from aqueous solutions by the ZSM-5 zeolite. Journal of Molecular Liquids 2015; 207: 338-342.

22. ELBOUGHDIRI N. The use of natural zeolite to remove heavy metals $\mathrm{Cu}$ (II), $\mathrm{Pb}$ (II) and Cd (II), from industrial wastewater. Cogent Engineering 2020; 7: 1-13.

23. Rashad M, Salim M.E, and Assad F.F. Removal of Some Environmental Pollutants from Aqueous Solutions by Linde-Zeolite: Adsorption and Kinetic Study. Advances in Environmental Biology, 2012; 6(5): 1716-1724

24. TAAMNEH Y, SHARADQAH S, The removal of heavy metals from aqueous solution using natural Jordanian zeolite. Appl. Water Sci. 2017; 7: 2021-2028.

25. MEHDIZADEH S, SADJADI S, AHMADI J.S and OUTOKESH M. Removal of Heavy Metals from Aqueous Solution Using Platinum Nanoparticles/Zeolite-4A. Journal of Environmental Health Science \& Engineering 2014; 12(7).

26. ERDEM E, KARAPINAR $\mathrm{N}$ and DOONAT R. The removal of heavy metal cations by natural zeolites. J. of Colloid and Interface Sci. 2004; (280): 309-314.

27. El-AZIM A.H, and MOURAD A.F. Removal of Heavy Metals Cd (II), Fe (III) and Ni (II), from Aqueous Solutions by Natural Zeolites and Application to Industrial Wastewater. Asian Journal of Environment \& Ecology 2018; 7(1): 1-13.

28. SALMAN H, SHAHEEN H, ABBAS G and KHALOUF N. Use of Syrian natural zeolite for heavy metals removal from industrial wastewater: Factors and mechanism. Journal of Entomology and Zoology Studies 2017; 5(4): 452-461.

29. Mohammed A.A, Zaid A.A. Utilization of Natural zeolite as ionexchange and sorbent material in the removal of iron. Desalination 2008; 225: 70-81.

30. RAJAKRISHNAMOORTHY P, ELAVARASAN G, KARTHIKEYAN D, SARAYANAN G.C. Emission Reduction in SI Engines by using metal doped Cu- ZSM5 and Ce-Cu-ZSM5 zeolite as Catalysts. International Journal of Innovative Technology and Exploring Engineering 2019; 8(9): 1423-1427.

31. PRASANNA V.D et al. Investigation of Nitrogen Reduction in Four Stroke Petrol Engine Using Zeolites As Adsorbent. Research Journal of Life Sciences, Bioinformatics, Pharmaceutical and Chemical Sciences 2019; 5(2): 897.

32. SIRIWARDANE V.R, Shen S.M, and Fisher P.E. Adsorption of CO2, N2, and O2 on Natural Zeolites. Energy \& Fuels 2003; 17: 571-576.

33. Souza C.V, Rocha V.J, Araujo G.J.M, SAPAG K, and PERGHER C.B.S. Basic Treatment in Natural CLINOPTILOLITE for Improvement of Physicochemical Properties. Mineral 2018; 8: 595.

34. WANG C, LENG S, GUO H, CAO L, HUANG J. Acid and Alkali Treatments for regulation of hydrophilicity/hydrophobicity of natural zeolite. Applied Surface Science 2019; 478: 319-326.

35. NHA-406EN, Automotive Emission Analyzer. Retrieved from https://www.alibaba.com/product-detail/07172255060.html; October $10,2020$.

36. CHAHAN Y.P, and TALIBA I.M. Design of Laboratory Scale Packed Bed Column for Adsorption of Phenol on to Modified Coal Fly Ash (MCFA). International Journal of Sci., Eng. and Tech. Research 2017; 6(4): 2278 -7798.

37. DJAMBAZOV S, YOLVA A. An Effect of a Natural Zeolite on the Characteristics of spring or Electrochemically Activated Water. Journal of Chemical Technology and Metallurgy 2018; 53(6):11951202.

38. Wang X, Shao D, Hou G, Wang X.K, Alsaedi A, Ahmad B. Uptake of $\mathrm{Pb}$ (II) and $\mathrm{U}$ (VI) ions from aqueous solutions by the ZSM-5 zeolite. Journal of Molecular Liquids 2015; 207: 338-342.

Published By:

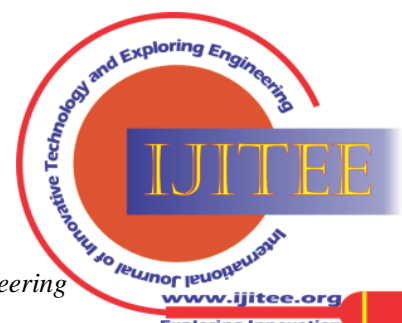


39. MEHDIZADEH S, SADJADI S, AHMADI JS and OUTOKESH M. Removal of Heavy Metals from Aqueous Solution Using Platinum Nanoparticles/Zeolite-4A. Journal of Environmental Health Science \& Engineering 2014; 12(7).

40. HUANG SL, NG CO, GUO QZ, Experimental investigation of the effect of flow turbulence and sediment transport patterns on the adsorption of cadmium ions onto sediment particles. Journal of Environmental Sciences 2007; 19: 696-703.

41. HELFFERICH F. Ion Exchange. New York. Dover Publications. 1995. Retrieved from https://files.isec.pt BIBLIO; November 14 2020.

42. ZORPAS AA, VASILIS I, LOIZIDOU M, and GRIGOROPOULOU H. Particle Size Effects on Uptake of Heavy Metals from Sewage Sludge Compost Using Natural Zeolite Clinoptilolite. J. of Colloid and Interface Sci. 2002; 250: 1-4.

43. WINGENFELDER U, HANSEN C, FURER G, SCHULIN R. Removal of heavy metals from mine waters by natural zeolites environ. Sci. Technol. 2005; 39: 4606-4613.

44. ÖREN H.A and KAYA A. Factors Affecting Adsorption Characteristics of $\mathrm{Zn}^{2+}$ on Two Natural Zeolites. Journal of Hazardous Materials 2006; 131(B): 59-65.

\section{AUTHORS PROFILE}

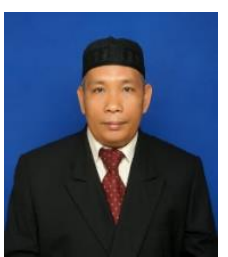

Amru Siregar; obtained a Bachelor's degree in Mechanical Engineering from the Faculty of Engineering, University of North Sumatra, Medan, Indonesia, and earned a Master's degree in Mechanical Engineering from the Faculty of Engineering, Gadjah Mada University, Yogyakarta, Indonesia. Several studies that have been conducted include; Effect of chromizing ASSAB 709 steel on fatigue behavior, as a thesis; Improved Fatigue Properties of Chromized Steel NS-1045 by Heat Treatment Process; Effect of Acrylic Acid on the thermal Properties of Coconut Shell Filled Low Density Polyethylene Composite; Design of Natural Zeolite adsorption Media as Adsorbent in Automotive Engine Gas Emissions, Journal of Mechanical Engineering Materials and Energy Manufacturing; Acoustic Characteristics of Coconut Coir Fiber. Profession as a lecturer in the Mechanical Engineering study program, Faculty of Engineering, University Medan Area, Indonesia.

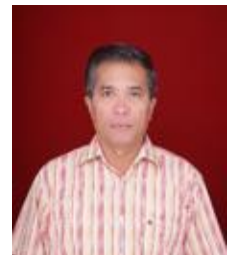

Amirsyam Nasution; obtained a Bachelor's degree in Mechanical Engineering from the Faculty of Engineering, University of North Sumatra, Medan, Indonesia. While the Master degree in Mechanical Engineering from the Faculty of Mechanical and Aerospace Engineering, Bandung Institute of Technology, Indonesia. Several studies that have been carried out include; Effect of Heat, Air Mass Flow Rate and Temperature on Rice Drying Time Using Rotary Type Dryer, Journal of Sustainable Engineering and Technology Innovation and Application; The Effect of Addition of $\mathrm{Sr}$ and $\mathrm{TiB}$ on $\mathrm{Al}-\mathrm{Si}-\mathrm{Cu}-\mathrm{Mg}$ Aluminum Alloys to produce Motorcycle Cylinder Head Prototypes, Journal of the International Society of Ocean, Mechanical and Aerospace Scientists and Engineers. Profession as a lecturer in the Mechanical Engineering study program, Faculty of Engineering, University of Medan Area, Indonesia. 